\title{
Design and simulation of coaxial self-vibration and variable-frequency centrifuge of tube\&mould for new type well pipe
}

\author{
Jiangtao Liu ${ }^{1, a}$, Zhang Xincai ${ }^{2, b}$, Degang Kong ${ }^{1, a}$, Yongwei Yuan ${ }^{1, a}$, Honglei \\ $\mathrm{Wu}^{1, \mathrm{a}}$ \\ ${ }^{1}$ Mechanical \& Electronic Engineering College, Agricultural university of Hebei, Baoding 071001 \\ ${ }^{2}$ Hebei Xinqingyuan Shiye Co., Ltd., Baoding 071100 \\ aemail: liujiangtao2003@126.com, bemail: jzbysj2006@126.com
}

Keywords: centrifuge; simulation; tube\&mould; hydraulic

\begin{abstract}
Coaxial self-vibration and variable-frequency centrifuge of tube\&mould for new type well pipe is composed of variable-frequency control system, hydraulic system, pressure device, self-vibration wheel, tube\&mould, hydraulic supporting and protection device, transmission device and motor etc. Transmission device, pressure device and tube\&mould is coaxial in the long distance and tube\&mould is supported by the hydraulic supporting and protection device in the middle position to solve the eccentric problem of the well pipe production. The small vibration of self-vibration wheel and the variable-frequency speed regulation of electronic control are combined to improve the molding speed, density and uniformity of well pipe. Both ends of tube\&mould are provided with the independent elastic clamping device and the sealing effect is good. Based on the requirement of hydraulic system of coaxial natural vibration and frequency conversion centrifuge, the mathematical model of hydraulic system is established. And then the simulation and analysis are performed by using MATLAB.
\end{abstract}

\section{Introduction}

At present, the prestressed reinforced concrete well pipe (new type well pipe) is produced by mainly using the ground wheel type centrifuge. Ground wheel type centrifuge is generally composed of motor, gear box, transmission axis, and two or more than two groups of ground wheel consisted of two to three wheels. When working, the crane transports tube\&mould of filler to ground wheel. And then motor is start. After the rotating speed is changed by the gearbox, the transmission axis drives tube\&mould rotate through the ground wheel to mold the concrete well pipe. Due to solely rely on the supporting of the ground wheel to make tube\&mould rotate, tube\&mould is easy to jump up and down. The collision of the centrifuge and tube\&mould damages the mould and the centrifuge. The noise is large and the centrifuge and tube\&mould are often maintained. At the same time, well pipe produced by the ground wheel type centrifuge is easy to appear the eccentricity (the well pipe wall thickness is not uniform). The eccentric concrete well pipe is easy to be broken in the course of transportation or down well. Because both ends of tube\&mould are open, the running slurry in the centrifugal molding affects the quality of well pipe $[1,2,3,4,5]$

\section{Overall Technology}

Coaxial self-vibration and variable-frequency centrifuge of tube\&mould for new type well pipe is composed of variable-frequency control system, hydraulic system, pressure device, pressure locking head, self-vibration wheel, tube\&mould, hydraulic supporting and protection device, transmission locking head, transmission device and motor etc. Coaxial self-vibration and variable-frequency centrifuge of tube\&mould for new type well pipe is shown in Fig.1. The centrifuge finishes the whole process of start-up, acceleration, well pipe centrifugal molding, braking and parking with a start button. And the molding cycle is short and the efficiency is high. 


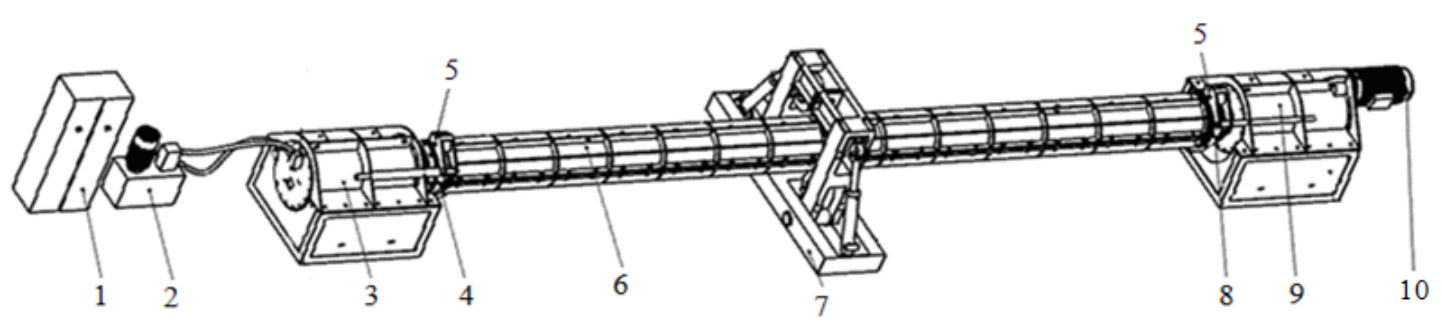

1.variable-frequency control system 2.hydraulic system 3.pressure device 4.pressure locking head 5.self-vibration wheel 6.tube\&mould 7.hydraulic supporting and protection device 8.transmission locking head 9. transmission device 10. motor

Fig.1. Coaxial self-vibration and variable-frequency centrifuge of tube\&mould

To solve the eccentric problem of the well pipe production, transmission device, pressure device and tube\&mould are coaxial in the long distance. Tube\&mould is supported by the hydraulic supporting and protection device in the middle position. Coaxial self-vibration and variable-frequency centrifuge of tube\&mould can produce well pipe from 1 to $18 \mathrm{~m}$. Well pipe of the different models/specifications accords with the standard of concrete and reinforced concrete well pipe industry standards. The actual measured pass rate is more than $99.8 \%$ and the well depth can reach $600 \mathrm{~m}$. The self-vibration wheel is symmetrically set up on the pressure locking head and transmission locking head. The small vibration is put on the pressure locking head and transmission locking head and the small vibration and the variable-frequency speed regulation of electronic control are combined to improve the molding speed, density and uniformity of the prestressed reinforced concrete well pipe. The productivity is increased by 2 times comparison with old type centrifuge and the density is high. Both ends of tube\&mould is provided with the independent elastic clamping device, which is convenient to replace and has the good sealing effect, to solve the problem of the slurry and avoid the slurry forming the waste residue, improve the environment of the well pipe production, save the energy and protect the environment. When tube\&mould rotates, tube\&mould above $8 \mathrm{~m}$ is supported by the hydraulic supporting and protection device in order to prevent the well pipe from jumping up and down and damaging the centrifuge, avoid the well pipe eccentricity(the well pipe wall thickness is not uniform) and increased the life span of centrifuge and tube\&mould.

\section{Key Parts Design}

Transmission Device. Transmission device is mainly composed of driving motor, reduction gear, driving axis, transmission locking head, self- vibration wheel and elastic clamp. The transmission device is shown in Fig.2.

When working, the speed of transmission device is up to about $550 \mathrm{r} / \mathrm{min}$. Motor selects four phase AC motor. The rotating speed of AC motor is adjusted through the frequency converter. The rotating speed is decelerated to the specified speed by the harmonic-planetary gear box. Because the inertia moment of tube\&mould, transmission locking head and pressure locking head is large, the reduction mechanism is selected. When parking, reduction mechanism can reduce the inertia moment by the ratio of the square to avoid damaging the centrifuge and tube\&mould.

Pressure Device. Pressure device is mainly composed of pressure cylinder, pressure locking head, self- vibration wheel and elastic clamp. The pressure device is shown in Fig.3.

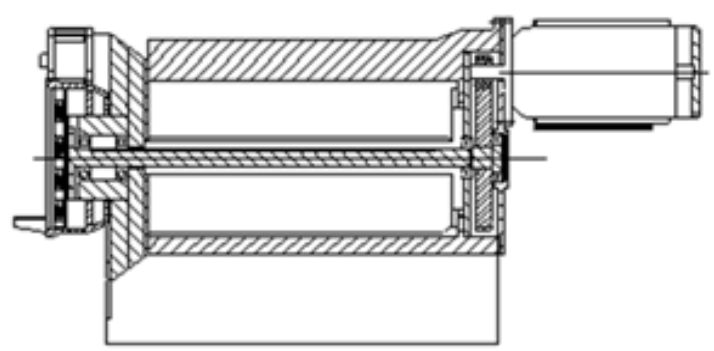

Fig.2. Transmission device

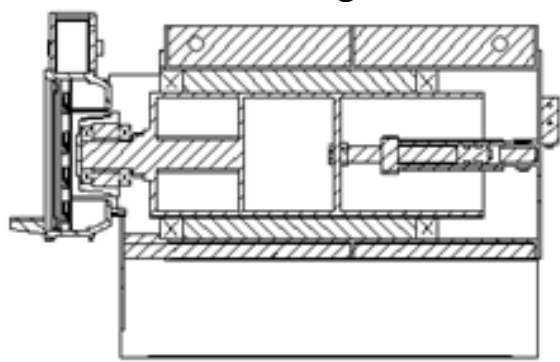

Fig.3. Pressure device 
Before working, pressure cylinder extends to comprise the independent elastic clamp. Both ends of tube\&mould are sealed. At the same time, two ends of tube\&mould and locking head generate the extrusion force so that the friction force is generated when the centrifugal rotates and the torque is transferred.

Hydraulic Supporting and Protection Device. Hydraulic supporting and protection device supports and protects tube\&mould in order to prevent the well pipe from jumping up and down and the well pipe eccentricity (the well pipe wall thickness is not uniform). Hydraulic supporting and protection device is shown in Fig.4.

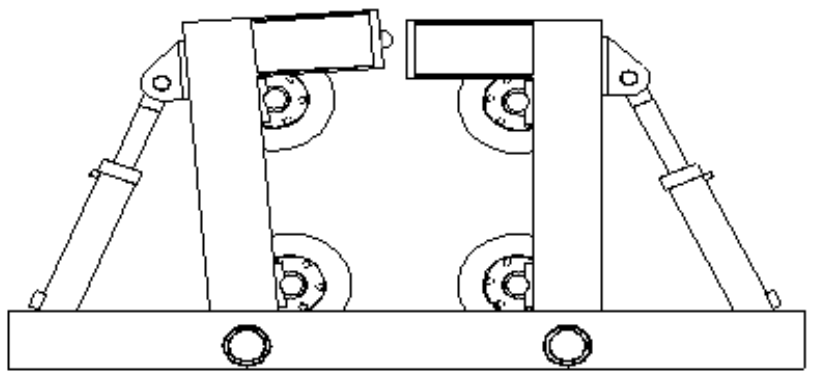

Fig.4. Hydraulic supporting and protection device

When working, the hydraulic control system drives the hydraulic cylinder piston rod extend to hold tube\&mould through the supporting wheel. The supporting wheel supports and protects tube\&mould. When tube\&mould rotates, the supporting wheel rotates with the pipe body also. After the centrifugal is finished, the hydraulic control system controls the hydraulic cylinder of hydraulic supporting and protection device to retract. The crane transports tube\&mould to steam curing pond. The hydraulic supporting and protection device can effectively prevent tube\&mould from jumping up and down and damaging tube\&mould to solve the eccentric problem of the production of well pipe. Well pipe from 1 to $18 \mathrm{~m}$ can be produced. At the same time, the noise is low and the operation is stable. And the life of tube\&mould and the centrifuge are improved.

\section{Hydraulic System Simulation}

Pressure device of coaxial self-vibration and variable-frequency centrifuge of tube\&mould for new type well pipe adopts the hydraulic automatic control. Pressing device can be controlled in real time and smoothly move. At the same time, Pressing device can be adjusted in real time, stable and reliable in the operation process. So the hydraulic control system uses the valve control hydraulic cylinder to drive pressure device extend and retract. The open loop transfer function of the hydraulic system is as follow:

$$
G(s)=\frac{43500 s^{2}+1.654 \times 10^{7} s+3.34 \times 10^{9}}{3.87 s^{4}+1910 s^{3}+2.832 \times 10^{6} s^{2}+1.317 \times 10^{9} s+2.795 \times 10^{8}}
$$

The unit step responsive curve and the bode diagram are respectively drawn by using step and Bode in MATLAB toolbox. Be shown in Fig.5 and Fig.6.

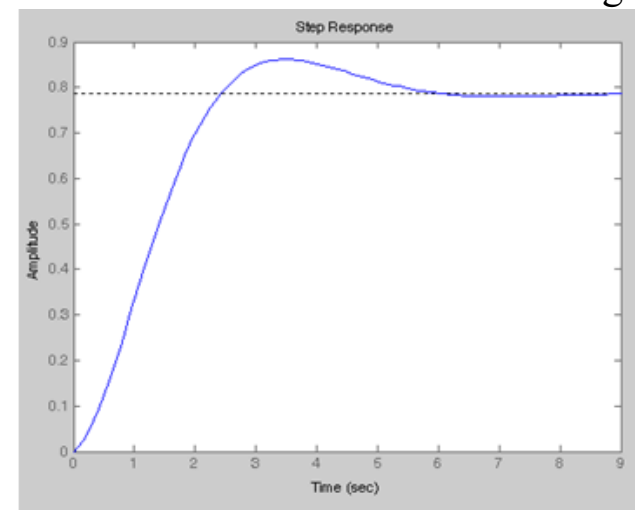

Fig.5. Unit step responsive curve

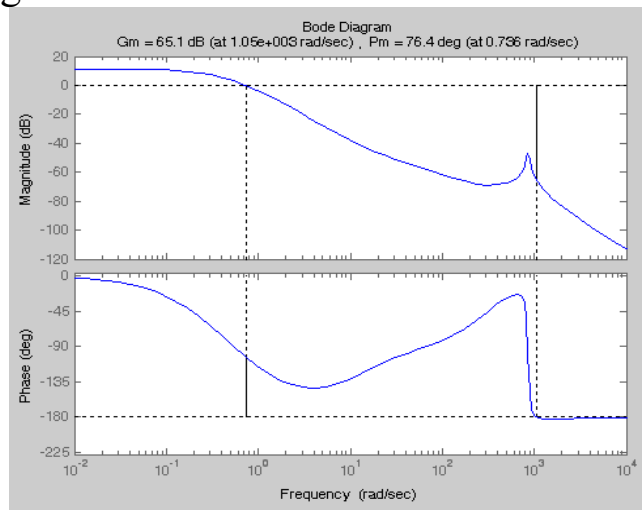

Fig.6. Bode diagram 
From Fig.5 and Fig.6, it is shown that the hydraulic system is stable and fast, the overshoot is small, the steady-state accuracy is high; the amplitude margin and the phase margin are satisfied with the requirement, and the hydraulic system stability is good.

\section{Conclusion}

Transmission device, pressure device and tube\&mould are coaxial in the long distance. Tube\&mould is supported by the hydraulic supporting and protection device in the middle position to solve the eccentric problem of the well pipe production. Well pipe from 1 to $18 \mathrm{~m}$ can be produced. The actual measurement pass rate is more than $99.8 \%$ and the well depth can reach $600 \mathrm{~m}$. Both ends of tube\&mould is provided with the independent elastic clamping device, which is convenient to replace and has the good sealing effect, to solve the problem of the slurry and avoid the slurry forming the waste residue, improve the production environment of well pipe production. The wheel self-vibration and the variable-frequency speed regulation of electronic control are combined to improve the molding speed, density and uniformity of well pipe. The productivity is increased by 2 times comparison with old type centrifuge and the density is high. MATLAB simulation shows that the hydraulic system is stable and reliable.

\section{Acknowledgement}

In this paper, the research was sponsored by Science and Technology Research Project of 2016 Colleges and Universities of Hebei Province (Project No. ZC2016159)

\section{References}

[1] Ceng Keping. Technical measures to ensure the quality of well pipe construction [J]. WEST-CHINA EXPLORATION ENGINEERING, 2005, (110): 45-46.

[2] ZHANG Jian, JIA Xiao-xia, NIU Wei, ZHAN Zhe-jun. Matlab simulation and hardware realization of SVPWM frequency converter[J]. ELECTRIC DRIVE AUTOMATION, 20097, 31(1): 10-11.

[3] Zhang Yunguo, Li Fenglan, Gao Rundong. Study on properties of steel fiber reinforced concrete by centrifugal method[J]. China Concrete and Cement Products, 2005, (2): 38-40.

[4] XUN Li, LONG Ying.Research on Simulation Method Based on Matlab Simulink [J]. Science Technology and Engineering, 2005, 5(14): 1018-1019.

[5] ZHU Yong-chao, ZHAO Gang.A Research on IGBT Turn-on Model Based on MATLAB /Simulink [J]. Power System \& Automation, 2015, 37(6): 56-59. 